\title{
Exercise training decreases in vitro stimulated lipolysis in a visceral (mesenteric) but not in the retroperitoneal fat depot of high-fat-fed rats
}

\author{
Natalie Chapados ${ }^{1}$, Pascal Collin ${ }^{1}$, Pascal Imbeault ${ }^{2}$, Pierre Corriveau ${ }^{1}$ and Jean-Marc Lavoie ${ }^{1 *}$ \\ ${ }^{1}$ Département de Kinésiologie, Université de Montréal, Montreal, Quebec, Canada H3C $3 \mathrm{~J} 7$ \\ ${ }^{2}$ Department of Human Kinetics, University of Ottawa, Canada
}

(Received 5 June 2007 - Revised 30 October 2007 - Accepted 20 December 2007 - First published online 20 February 2008)

The purpose of the present study was to determine the effects of an exercise training programme in high-fat-fed rats on in vitro lipolysis in a visceral (mesenteric) and a non-visceral fat depot (retroperitoneal) and its relationship to perilipin content. Two groups of female rats were fed a high-fat diet ( $42 \%$ as energy) for 8 weeks, one remaining sedentary (Sed) and the other being exercise trained (Tr) for this entire period. Rats were killed after 2 and 8 weeks of their respective treatment. The significantly $(P<0 \cdot 01)$ higher levels in mesenteric and retroperitoneal fat pad weights, plasma leptin, NEFA and glucose observed with time in Sed high-fat-fed rats were significantly $(P<0 \cdot 05)$ attenuated in $\mathrm{Tr}$ animals. Isoproterenol-stimulated $\left(10^{-5}-10^{-4} \mathrm{M}\right)$ lipolysis in the mesenteric, but not in the retroperitoneal tissue, was significantly $(P<0.05)$ lower (about 57\%) in Tr than in Sed rats after 8 weeks of high-fat feeding. The isoproterenol-stimulated lipolysis in the mesenteric tissue of 8 -week Tr high-fat-fed rats was lowered to the level measured in 2-week fat-fed rats although mesenteric fat accumulation was still significantly $(P<0.01)$ higher in 8- than in 2-week Tr rats. Perilipin content (Western blot) was not affected by the exercise training programme. These results indicate that exercise training resulted in a reduction in the high-fat diet-induced elevated levels of lipolysis in the mesenteric tissue. This response appears to be independent of the perilipin content.

Non-esterified fatty acids: Perilipin: Isoproterenol-induced lipolysis: Leptin: Fat mass

When present in excess, plasma NEFA are involved directly in the pathogenesis of metabolic disturbances leading to insulin resistance and the metabolic syndrome ${ }^{(1)}$. It has been suggested in animal as well as human studies that increased fat accumulation inside the adipocyte results in an increased lipolysis, thus resulting in increased plasma NEFA levels ${ }^{(2)}$. Regulation of lipolysis, especially in the visceral compartment ${ }^{(3)}$, is, therefore, important for the prevention of systemic metabolic disorders.

Since the typical Western diet is very high in fat, high-fatdiet regimens have been used frequently in animals as a model of obesity ${ }^{(4,5)}$ and more recently as a model to study the shortterm development of obesity ${ }^{(6,7)}$. It is generally assumed that a high-fat-diet regimen leads to an increased basal and stimulated adipocyte lipolysis, thus contributing to increased plasma NEFA levels ${ }^{(8,9)}$. On the other hand, exercise training has been reported to significantly reduce adipocyte fat accretion and plasma NEFA levels whether conducted concurrently or initiated during the course of a high-fat diet-induced obesity $^{(6,7)}$. Stimulated lipolysis in adipocytes has been shown to be increased by exercise training in lean human (subcutaneous tissue) and animal adipose tissue ${ }^{(10,11)}$ under normal feeding conditions. Whether basal and/or stimulated adipocyte lipolysis is also increased with exercise training under high-fat diet conditions is not known. It would be metabolically more appropriate if exercise training, under high-fat diet conditions, would result in a decrease instead of an increase in lipolysis. In this regard, it is revealing that in pinealectomised rats, in which adipocytes' lipolytic response to isoproterenol is increased, exercise training resulted in a decrease in this elevation in the epidymal fat $\operatorname{pad}^{(12)}$. The main purpose of the present study was to test the hypothesis that exercise training in high-fat-fed animals is associated with a reduction in adipocyte lipolysis. This was tested in a visceral (mesenteric) and in a non-visceral (retroperitoneal) fat tissue. Visceral fat (i.e. omental, mesenteric) is usually associated more strongly with metabolic abnormalities such as dyslipidaemia, hypertension, insulin resistance and type 2 diabetes than is subcutaneous or total body fat ${ }^{(13)}$. Catecholamine-induced rate of NEFA mobilisation from visceral fat cells is accelerated due to elevated rate of lipolysis in human obesity, mainly because of an increased $\beta$-3-adrenoceptor function, and a decreased $\alpha$-2-adrenoceptor function. This promotes an increased release of NEFA to the portal system, which may contribute to the parallel metabolic disturbances observed in upper-body obesity ${ }^{(14)}$. A reduction in the elevated lipolysis, especially in the mesenteric tissue with exercise training in high-fat-fed rats would, therefore, constitute an asset in reducing the increased amount of NEFA reaching the portal system.

In recent years, a new component regulating the activity of hormone-sensitive lipase (HSL)-mediated lipolysis has been identified. Perilipins are phosphoproteins in adipocytes 
localised at the surface of the lipid droplet ${ }^{(15)}$. There is evidence that the access of HSL to the lipid droplets is determined by perilipin $A$, the main isoform of perilipin ${ }^{(16,17)}$. Increased basal lipolysis in high-fat-fed rats may result from an increase in HSL mass or activity; alternatively, this increase may reflect the absence of a protective coat of perilipin on the lipid droplet ${ }^{(18)}$. There is no information on the action of exercise training on perilipin in adipocytes. It has previously been suggested that exercise training might alter the amount of perilipin, thereby regulating the interaction of HSL with its substrate ${ }^{(19)}$. In an effort to better understand how lipolysis may be affected by exercise training in highfat-fed rats, we measured perilipin protein content and tried to associate it with changes in in vitro lipolysis in the mesenteric tissue.

\section{Methods}

\section{Animal care}

Female Sprague-Dawley strain rats ( $n$ 45) (Charles River, St-Constant, PQ, Canada), weighing 180-200 g upon their arrival were housed individually and had ad libitum access to food and tap water. Their environment was controlled in terms of light $(12 \mathrm{~h}-12 \mathrm{~h}$ light-dark cycle starting at 06.00 hours), humidity and room temperature $\left(20-23^{\circ} \mathrm{C}\right)$. All experiments described in this report were conducted according to the directives of the Canadian Council on Animal Care.

\section{Diet and exercise protocol}

A few days after their arrival, all animals were assigned to a high-fat diet while remaining sedentary (Sed) or being submitted to an exercise training programme (Tr) for 2 or 8 weeks (nine rats per group). Another group of rats were immediately killed to provide basal values $(\mathrm{T}=0 ; n 6-9)$. The high-fat diet consisted of $42 \%$ lipid ( $80 \%$ lard, $20 \%$ maize oil), $36 \%$ carbohydrate, and $22 \%$ protein (by energy content) and was provided in small pellets from ICN Pharmaceuticals (Plainview, NY, USA). Details of this diet have been presented elsewhere ${ }^{(6)}$. The exercise training programme was introduced concomitantly to the high-fat diet. Exercise training consisted of continuous running on a motor-driven rodent treadmill (Quinton Instruments, Seattle, WA, USA) five times per week for the duration of the experiment. During the first 2 weeks, rats were progressively run from $15 \mathrm{~min} / \mathrm{d}$ at $15 \mathrm{~m} / \mathrm{min}, 0 \%$ slope up to $30 \mathrm{~min} / \mathrm{d}$ at $26 \mathrm{~m} / \mathrm{min}$, $4 \%$ slope. Thereafter, the training programme was progressively increased to reach $60 \mathrm{~min}$ at $26 \mathrm{~m} / \mathrm{min}, 10 \%$ slope for the last 4 weeks. All $\mathrm{Tr}$ animals were restrained from training $48 \mathrm{~h}$ before killing.

\section{Blood and tissue sampling}

At the end of their respective experimental condition, all animals were weighed and killed between 08.30 and 10.30 hours. Food was removed from the animals at least $2 \mathrm{~h}$ before killing. After complete anaesthesia (sodium pentobarbital, $50 \mathrm{mg} / \mathrm{kg}$, intraperitoneal), the abdominal cavity was rapidly opened following the median line of the abdomen. Blood was rapidly $(<45 \mathrm{~s})$ drawn from the abdominal vena cava (about $4 \mathrm{ml}$ ) into syringes pre-treated with EDTA $(15 \%)$. Blood was centrifuged $\left(4000 \mathrm{rpm}\right.$ for $10 \mathrm{~min}, 4^{\circ} \mathrm{C}$ ) and the plasma kept for NEFA, glucose, insulin and leptin determinations. The mesenteric and retroperitoneal fat depots were, thereafter, rapidly excised and weighed. The mesenteric fat pad consisted of adipose tissue surrounding the gastrointestinal tract from the gastro-oesophageal sphincter to the end of the rectum with special care taken in distinguishing and removing pancreatic cells. The retroperitoneal fat pad was taken as that distinct deposit behind each kidney along the lumbar muscles. About $700 \mathrm{mg}$ of the depots was immediately used for determination of lipolysis. The remaining portions of the mesenteric and retroperitoneal depots as well as plasma samples were stored at $-78^{\circ} \mathrm{C}$ until analyses.

\section{Preparation of isolated adipocytes}

Adipocytes were isolated according to the method of Rodbell $^{(20)}$. Tissue fragments $(700 \mathrm{mg})$ from the mesenteric and the retroperitoneal tissue were minced in polyethylene vials containing Krebs-Ringer bicarbonate buffer in the presence of collagenase P (1 mg/ml) (Roche 1213865; Mannheim, Germany). Krebs-Ringer bicarbonate buffer also contained fatty acid-free bovine serum albumin $(4 \%)$ and glucose $(0.5 \mathrm{~g} / \mathrm{l})$ (Krebs-Ringer bicarbonate buffer + albumin; KRBA). Thereafter, the atmosphere of the flasks was saturated with $95 \%$ $\mathrm{O}_{2}$ and $5 \% \mathrm{CO}_{2}$. Adipocytes were then incubated in a shaking water-bath at $37^{\circ} \mathrm{C}$ for $30 \mathrm{~min}$ with a shaking frequency of 100 strokes/min. The digested pieces were filtered through a nylon mesh for separation of fat cells from the stroma. The filtrate was collected in a graduated polyethylene tube to avoid cell breakage. The aqueous phase was aspirated with polyethylene pipettes. The floating adipocytes were then re-suspended in $5 \mathrm{ml}$ of fresh KRBA. This process was repeated three times to eliminate the remaining collagenase. The adipocytes were stored in the KRBA for 2 min between two washes.

\section{Incubation of adipocytes and measurement of lipolysis}

Basal and stimulated lipolysis was determined in isolated adipocytes $(50 \mu \mathrm{l})$ incubated with a $10 \mathrm{ul}$ solution of KRBA buffer and ascorbic acid (basal) and with isoproterenol adjusted to give concentrations of $10^{-7}, 10^{-5}$ and $10^{-4} \mathrm{M}$. Isoproterenol was used because it is a pure $\beta$-agonist and as such it elicits the greatest lipolytic response ${ }^{(8)}$. Isoproterenol produced a dosedependent increase in lipolysis, with the maximal responses (plateau) reached at $10^{-4}$ and $10^{-5} \mathrm{M}$. In agreement with other groups, adenosine deaminase was not added to the incubation medium to block the anti-lipolytic action of adenosine ${ }^{(21,22)}$. The incubation was performed at $37^{\circ} \mathrm{C}$ under a $95 \% \mathrm{O}_{2}-5 \%$ $\mathrm{CO}_{2}$ atmosphere with gentle shaking (eighty strokes per min) for $2 \mathrm{~h}$. The reaction was stopped by adding $50 \mu \mathrm{HCl}(1 \mathrm{M})$ and then $50 \mu \mathrm{l} \mathrm{NaOH}(1 \mathrm{M})$ to neutralise the medium. The vials were vortexed and put on ice for $10 \mathrm{~min}$. After a centrifugation of $5 \mathrm{~s}$ at $250 \mathrm{~g}$, the aqueous phase was removed and stored at $-78^{\circ} \mathrm{C}$ until glycerol determination.

Lipolytic activity was measured by glycerol quantification with the use of commercially available kits from Roche Diagnostics (Mannheim, Germany). Glycerol quantification was expressed in millions of cells/h after counting the number of cells in each tested sample. 


\section{Cell count}

The number of cells in each individual sample was determined by first diluting $100 \mu \mathrm{l}$ of the isolated adipocyte preparation into $9.9 \mathrm{ml} \mathrm{KRBA}(100 \mu \mathrm{l})$ and then dropping $50 \mu \mathrm{l}$ of this solution in $25 \mu \mathrm{l}$ of trypan blue $(0.4 \%$ normal saline). The total number of cells in this final suspension was determined with the use of a Nikon-optiphot microscope $(10 \times)$ and with Image-Pro plus version 4.5 (Media Cybernetics; Silver Spring, MD, USA).

\section{Measurement of perilipin content}

Mesenteric fat depots (about $100 \mathrm{mg}$ ) were homogenised in EDTA-sucrose buffer and centrifuged at $12000 \mathrm{~g}, 4^{\circ} \mathrm{C}$ for 20 min. The infranatant was collected with a blunt-tipped Pasteur pipette and stored at $-80^{\circ} \mathrm{C}$ until perilipin determination. Perilipin A content in adipocytes was determined by Western blotting. All samples ( $25 \mu \mathrm{g}$ of proteins) were separated on a $10 \%$ SDS-polyacrylamide gel followed by protein transfer to a polyvinylidene difluoride membrane by electroblotting. The membrane was blocked in $5 \%(\mathrm{w} / \mathrm{v})$ skimmed milk in TBS (100 mM-2-amino-2-(hydroxymethyl)propane-1,3-diol, $100 \mathrm{~mm}-\mathrm{NaCl}, \mathrm{pH} 7 \cdot 5$ ) for $2 \mathrm{~h}$ at room temperature before overnight incubation with a rat perilipin A polyclonal antibody (ABR-Affinity Bio Reagents) with $0.05 \%$ sodium azide. After three washes in TBS-Triton $0.5 \%$, the membrane was incubated for $1 \mathrm{~h}$ with an anti-rabbit IgG peroxidase-conjugated antibody (Jackson ImmunoResearch Laboratories, Inc., West Grove, PA, USA) diluted to $0.8 \mu \mathrm{g} / \mathrm{ml}$ in $0.1 \%$ bovine serum albumin, $0.1 \%$ Tween 20 and $1 \%(\mathrm{w} / \mathrm{v})$ skimmed milk in TBS. The membrane was washed three times for 10 min each time in TBS-Triton $0.5 \%$ before a chemifluorescence substrate (enhanced chemiluminescence; Amersham, Baie D'Urfée, PQ, USA) was applied to the membrane. The resulting signal was detected on enhanced chemiluminescence film (Amersham), scanned with the use of Agfas Arcus II, and quantified with Imagepro 4.5 software (Media Cybernetics, Silver Spring, MD, USA) and expressed as arbitrary units.

\section{Analytical procedures}

Plasma glucose concentration was determined with the use of a glucose analyser (Yellow Springs Instruments 2300; Yellow Springs, OH, USA). Plasma insulin levels were measured with commercially available kits from MP Biomedicals, LLC (Orangeburg, NY, USA). Plasma NEFA levels were measured with commercially available kits from Roche Diagnostics (Mannheim, Germany). Leptin levels were measured with commercially available kits from Linco (St Charles, MO, USA).

\section{Statistical analysis}

Values are expressed as mean values with their standard errors. Statistical analyses were performed by a two-way ANOVA for non-repeated-measures design with exercise training and time as main effects at times 2 and 8 weeks, excluding time point 0 (since no diet treatment was given at that time). In a second step, the effect of time was analysed separately in Sed and Tr rats using a one-way ANOVA for non-repeated measures over all time points using the same values at time 0 for both groups. This second statistical analysis was performed to better characterise the effect of time in each condition including comparison with time 0. Fisher's post hoc test was used in the event of a significant $(P<0.05) F$ ratio.

\section{Results}

Changes in body composition and metabolic characteristics of $\mathrm{Tr}$ and Sed rats are presented in Table 1 . The increase in body weight over time $(P<0 \cdot 01)$ was similar in Tr and Sed rats. The increase in the weight of the mesenteric and the retroperitoneal

Table 1. Body composition and metabolic characteristics of trained (Tr) and sedentary (Sed) rats at time week 0 (baseline values) and in response to 2 and 8 weeks of high-fat feeding (seven to nine rats/group)§ (Mean values with their standard errors)

\begin{tabular}{|c|c|c|c|c|c|c|c|}
\hline \multirow[b]{2}{*}{ High-fat feeding period } & & \multicolumn{2}{|c|}{0 weeks } & \multicolumn{2}{|c|}{2 week } & \multicolumn{2}{|c|}{8 weeks } \\
\hline & & Mean & SE & Mean & SE & Mean & SE \\
\hline \multirow[t]{2}{*}{ Body weight (g) } & Sed & 236 & $3 \cdot 0$ & $277^{\star \star}$ & $3 \cdot 6$ & $352^{\star *} \dagger \dagger$ & $13 \cdot 2$ \\
\hline & $\operatorname{Tr}$ & & & $283^{\star *}$ & $4 \cdot 8$ & $350^{* *}+\dagger$ & $12 \cdot 3$ \\
\hline \multirow{2}{*}{ Mesenteric fat pad (g) } & Sed & 3.33 & 0.24 & $5 \cdot 5$ & 0.3 & $13 \cdot 2^{\star \star}+\dagger$ & 1.4 \\
\hline & $\operatorname{Tr}$ & & & $5 \cdot 5^{\star}$ & 0.37 & 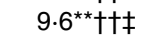 & $1 \cdot 0$ \\
\hline \multirow[t]{2}{*}{ Retroperitoneal fat pad (g) } & Sed & $1 \cdot 24$ & 0.14 & $3 \cdot 6^{\star \star}$ & 0.31 & $9 \cdot 4^{\star \star} \dagger \dagger$ & 0.66 \\
\hline & $\operatorname{Tr}$ & & & $3 \cdot 13^{\star *}$ & 0.25 & $6 \cdot 8^{\star *}+† \ddagger$ & 0.69 \\
\hline \multirow{2}{*}{ Leptin (ng/l) } & Sed & $1 \cdot 27$ & 0.2 & $3 \cdot 26^{\star *}$ & 0.25 & $6 \cdot 82^{\star \star}+\dagger$ & 0.39 \\
\hline & $\operatorname{Tr}$ & & & $2.44 \ddagger$ & 0.25 & $5 \cdot 51^{\star \star} † \dagger \ddagger$ & 0.53 \\
\hline \multirow[t]{2}{*}{ Plasma NEFA (mM) } & Sed & $0 \cdot 16$ & 0.01 & $0.29^{\star *}$ & 0.04 & $0.38^{\star \star}$ & 0.05 \\
\hline & $\operatorname{Tr}$ & & & $0.29^{\star \star}$ & 0.01 & $0.25^{\star \star} \ddagger$ & 0.04 \\
\hline \multirow[t]{2}{*}{ Glucose (mM) } & Sed & $5 \cdot 15$ & 0.45 & $7 \cdot 05^{\star \star}$ & 0.24 & $7 \cdot 82^{\star \star}$ & 0.21 \\
\hline & $\operatorname{Tr}$ & & & $7 \cdot 31^{\star \star}$ & 0.21 & $6 \cdot 69^{\star \star} \neq \ddagger$ & 0.28 \\
\hline \multirow[t]{2}{*}{ Insulin (pmol) } & Sed & $69 \cdot 3$ & 14 & 44 & 11 & $177 \dagger \dagger$ & 51 \\
\hline & $\operatorname{Tr}$ & & & $238^{\star \star} \neq \ddagger$ & 18 & $240^{\star *}$ & 33 \\
\hline
\end{tabular}

Mean value was significantly different from that at baseline (time 0 weeks): ${ }^{\star} P<0.05,{ }^{\star \star} P<0.01$

Mean value was significantly different from that at time 2 weeks: $+\uparrow P<0.01$.

Mean value was significantly different from that of the Sed group: $\ddagger P<0.05, \ddagger \ddagger P<0.01$

$\S$ All rats were fed a high-fat diet. 
fad pads, however, was higher $(P<0.05)$ in Sed than in Tr rats after 8 weeks of high-fat feeding. The same observation was made for plasma leptin levels, with higher $(P<0.05)$ values found in Sed than in Tr animals (Table 1). Plasma NEFA and glucose levels were also higher $(P<0 \cdot 01)$ with time in both $\mathrm{Tr}$ and Sed rats, but to a significantly $(P<0 \cdot 05)$ larger extent in Sed than in $\operatorname{Tr}$ animals. Plasma insulin levels were higher $(P<0.01)$ with time in both Tr and Sed rats (8 weeks).

Basal as well as stimulated lipolysis levels were higher with time $(P<0 \cdot 01)$ in the mesenteric tissue of Sed animals (Fig. 1). In $\operatorname{Tr}$ rats, basal lipolysis in the mesenteric tissue was not affected with time, while stimulated lipolysis was higher $(P<0.01)$ compared with time 0 but to a lesser extent than what was observed in Sed animals (Fig. 1). As a result, the elevation in stimulated lipolysis $\left(10^{-5}-10^{-4} \mathrm{M}\right)$ in the mesenteric tissue was lower $(P<0.05)$ in $\mathrm{Tr}$ than in Sed animals (week 8; Fig. 1). In the retroperitoneal tissue, however, stimulated lipolysis $\left(10^{-5}-10^{-4} \mathrm{M}\right)$ in $\mathrm{Tr}$ animals was increased to the same level as in Sed animals after 8 weeks, thus resulting in an absence of effects of training on lipolysis (Fig. 2).

Perilipin content in the mesenteric tissue expressed in arbitrary units was higher $(P<0.05)$ after 2 weeks in both Sed and $\operatorname{Tr}$ animals and decreased to initial values after 8 weeks (Fig. 3 (A)). This response was not significantly affected by the exercise training programme. When perilipin content

(A)

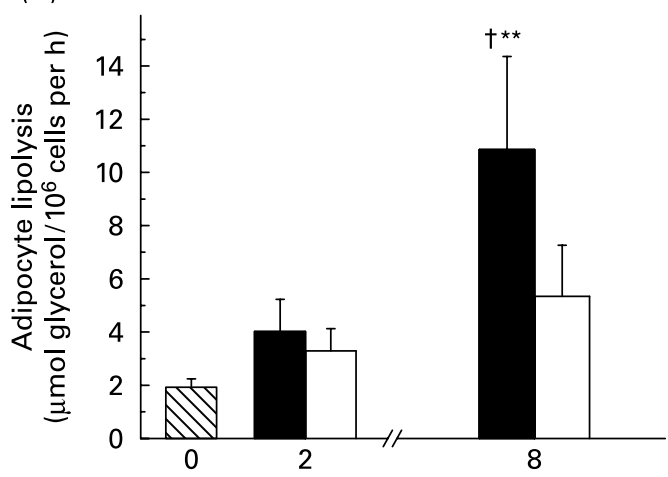

(C)

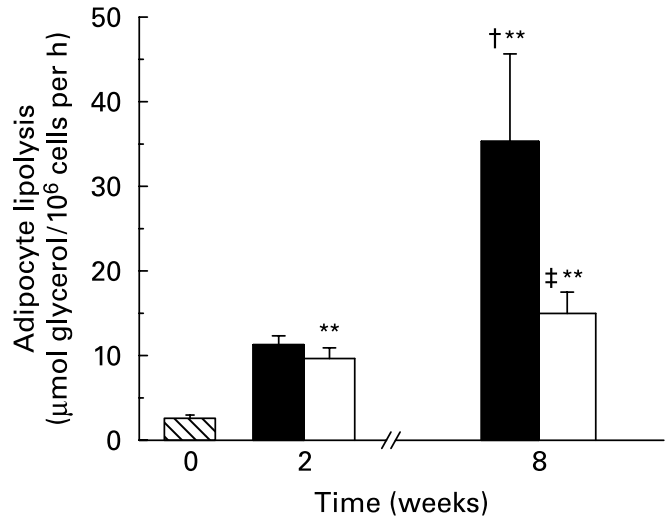

was expressed per unit of fat pad weight, significantly lower $(P<0.01)$ levels were found after 8 weeks compared with basal levels in both Sed and Tr animals (Fig. 3 (B)).

\section{Discussion}

In agreement with previous studies conducted in high-fat-fed rats ${ }^{(4,6,7)}$, exercise training in the present study resulted in a significant reduction in fat accumulation in the mesenteric and the retroperitoneal tissues along with lower levels of plasma NEFA and leptin (week 8; Table 1). In line with these observations, the most novel finding of the present study is that the high-fat-induced increase in isoproterenolstimulated lipolysis in the mesenteric tissue was reduced by 8 weeks of concurrent exercise training. This response is rather surprising considering that exercise training is generally associated with an increase, and not a decrease, in in vitro and in vivo stimulated adipose tissue lipolysis in normal dietary conditions ${ }^{(10,11,23)}$. The fact that the elevation in stimulated lipolysis was reduced by training in high-fat-fed-rats might, at first glance, simply reflect a reduction in fat mass in the mesenteric tissue. As mentioned by other studies ${ }^{(23)}$, this will not decrease the interest of the study since the reduction in fat mass is an effect of training. Most interestingly, however, stimulated lipolysis in the mesenteric tissue of 8 -week
(B)

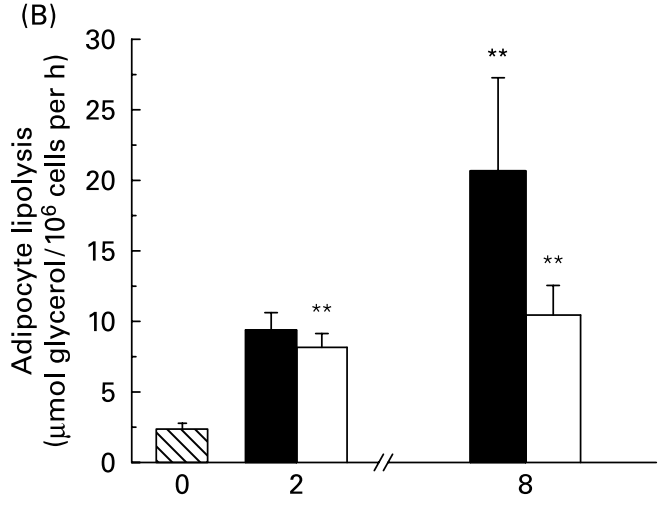

(D)

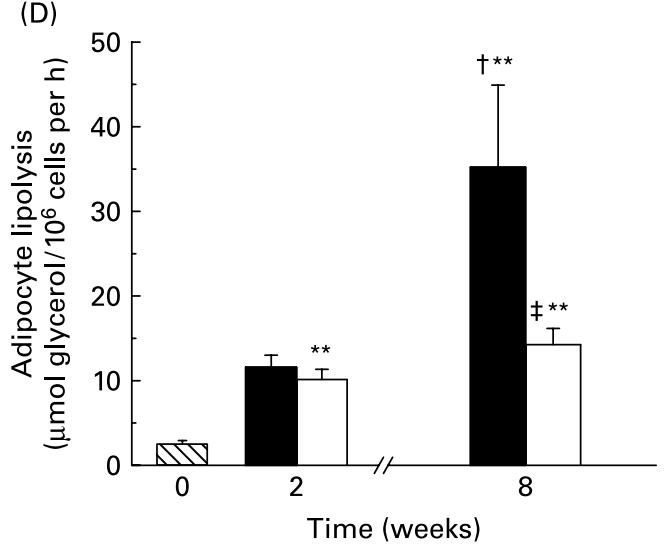

Fig. 1. Adipocyte lipolysis in mesenteric adipose tissue of sedentary $(\square)$ and trained $(\square)$ rats at time 0 weeks (baseline values; $\mathbb{\mathbb { N }}$ ) and in response to 2 and 8 weeks of high-fat feeding. Values are expressed as glycerol production per million cells per $\mathrm{h}$ in the basal state $(\mathrm{A})$ and in response to isoproterenol $\left(10^{-7} \mathrm{M}(\mathrm{B})\right.$; $\left.10^{-5} \mathrm{M}(\mathrm{C}) ; 10^{-4} \mathrm{M}(\mathrm{D})\right)$ after $2 \mathrm{~h}$ of incubation. Values are means for seven to nine rats per group ( $n 6$ at week 0 ), with standard errors represented by vertical bars. ${ }^{* *}$ Mean value was significantly different from that at baseline (time 0 weeks) $(P<0.01)$. $†$ Mean value was significantly different from that at 2 weeks $(P<0.05)$. $\ddagger$ Mean value was significantly different from that of the sedentary group $(P<0.05)$. 

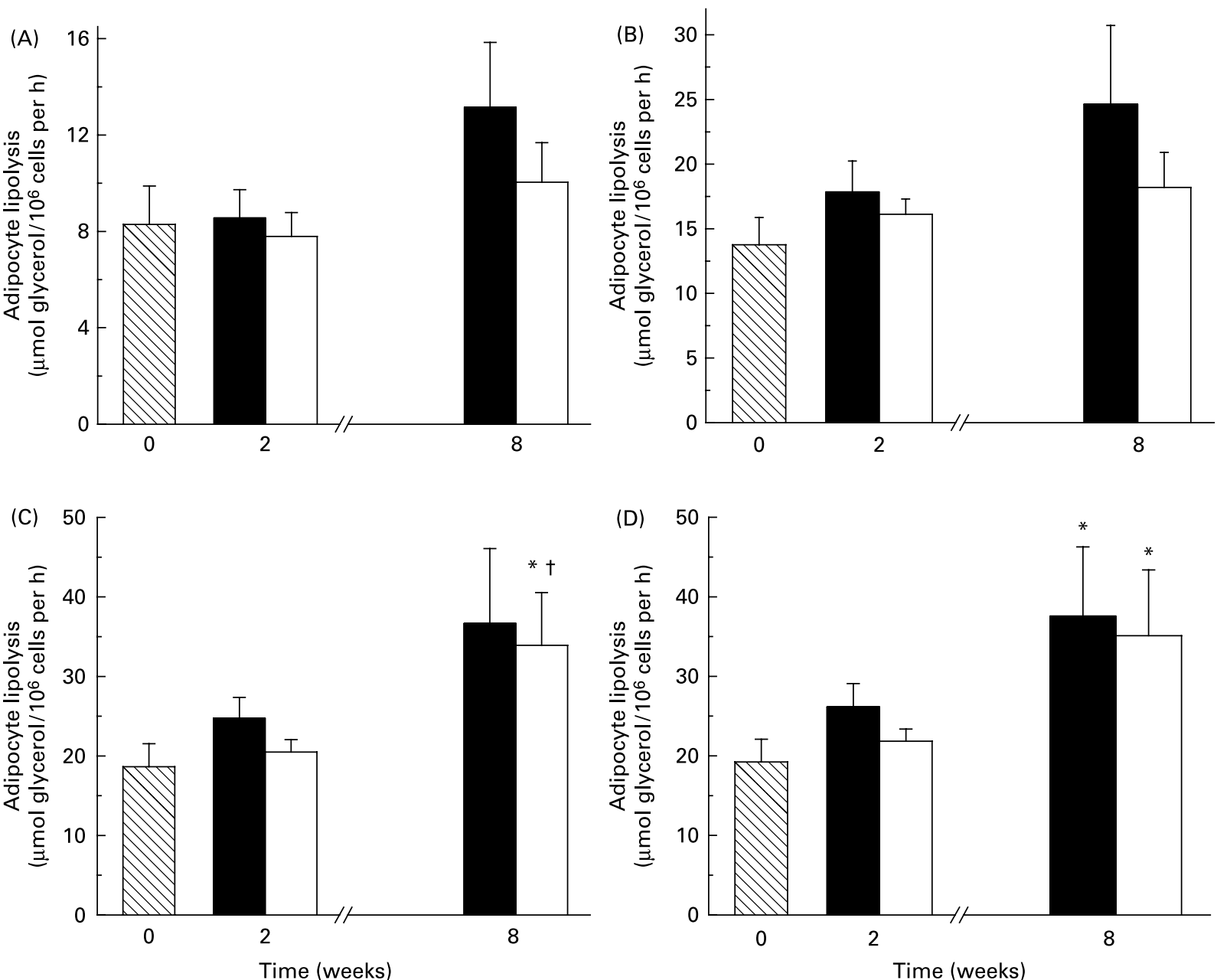

Fig. 2. Adipocyte lipolysis in retroperitoneal adipose tissue of sedentary $(\square)$ and trained $(\square)$ rats at time 0 weeks (baseline values; $\mathbb{Q}$ ) and in response to 2 and 8 weeks of high-fat feeding. Values are expressed as glycerol production per million cells per $\mathrm{h}$ in the basal state $(\mathrm{A})$ and in response to isoproterenol (10 ${ }^{-7} \mathrm{M}(\mathrm{B})$; $10^{-5} \mathrm{M}(\mathrm{C}) ; 10^{-4} \mathrm{M}(\mathrm{D})$ ) after $2 \mathrm{~h}$ of incubation. Values are means for seven to nine rats per group ( $n 6$ at week 0$)$, with standard errors represented by vertical bars. ${ }^{*}$ Mean value was significantly different from that at baseline (time 0 weeks) $(P<0.05)$. † Mean value was significantly different from that at 2 weeks $(P<0.05)$.

Tr rats was lowered to the level measured in 2-week-old rats even though fat accumulation was still about $75 \%$ higher in the former. This indicates that the large reduction in stimulated lipolysis in 8-week $\mathrm{Tr}$ rats cannot solely be attributed to the reduction in fat mass. Exercise training may act upon stimulated lipolysis in the mesenteric tissue of high-fat-fed rats so as to contribute to limit the amount of circulating NEFA resulting from daily sympathetic nerve activity. We previously reported that concurrent exercise conducted in high-fat-fed rats reduced plasma NEFA levels and completely prevented the high-fat diet-induced hepatic steatosis ${ }^{(6)}$. Taking into account that plasma NEFA levels reflect whole-body lipolysis, the present data extend these findings by being the first to indicate that under conditions of high-fat feeding exercise training reduced the elevation in isoproterenol-stimulated lipolytic activity of the mesenteric adipose tissue.

Although the present decrease in the elevation of isoproterenol-induced lipolysis with exercise training in the mesenteric tissue of high-fat-fed rats seems surprising, a similar finding has been recently reported in pinealectomised rats in which the absence of melatonin increased lipolysis ${ }^{(12)}$. Interestingly, the authors suggest that melatonin is necessary for the balance between lipogenesis and lipolysis of the adipocytes in response to physical training in rats. Although the molecular mechanism remains to be clarified, it is possible that exercise training under a high-fat feeding condition increased the lipogenic capacity of the visceral adipocytes to the detriment of lipolysis.

The interest of the present finding that exercise training reduced the elevation in stimulated lipolysis in the mesenteric tissue of high-fat-fed rats is exacerbated by the fact that the same observation was not made in the retroperitoneal tissue. Stimulated lipolysis in the retroperitoneal tissue was increased by about $95 \%\left(10^{-5}-10^{-4} \mathrm{M}\right)$ following 8 weeks of high-fat feeding. However, these increased lipolytic values were not affected by the exercise training programme (Fig. 2). In interpreting these data, it is important to recall that the retroperitoneal tissue, although considered an intra-abdominal tissue, is not a visceral tissue as is the intraperitoneal mesenteric depot $^{(24)}$. Accordingly, the high-fat feeding protocol increased stimulated lipolytic activity to a greater extent in the mesenteric (about ten-fold) than in the retroperitoneal tissue (about two-fold; Figs. 1 and 2) although relative fat accumulation was higher in the retroperitoneal than in the mesenteric 

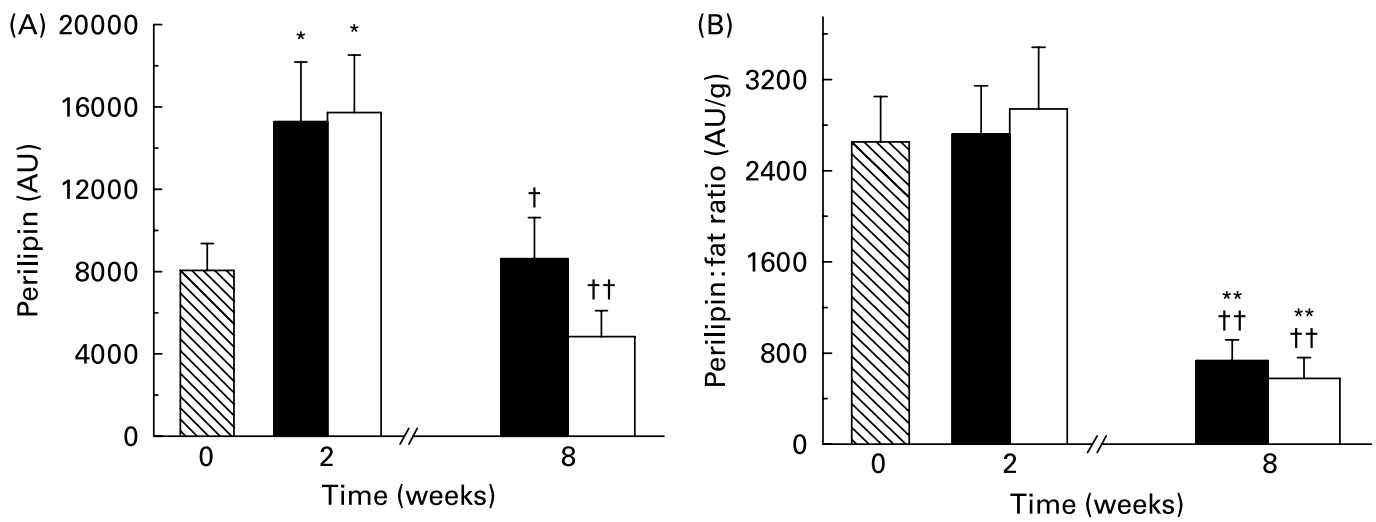

Fig. 3. Perilipin content $(A)$ and perilipin:fat ratio (B) measured in mesenteric tissue from sedentary $(\square)$ and trained $(\square)$ rats at time 0 weeks (baseline values; $\mathbb{Q}$ ) and in response to 2 and 8 weeks of high-fat feeding. Perilipin was measured by Western blotting and expressed in arbitrary units (AU). Perilipin:fat ratio was obtained by dividing the perilipin content by the absolute weight $(\mathrm{g})$ of the mesenteric depot. Values are means for eight to nine rats per group ( $n 6$ at week 0 ), with standard errors represented by vertical bars. Mean value was significantly different from that at baseline (time 0 weeks): ${ }^{*} P<0.05$, ${ }^{* *} P<0.01$. Mean value was significantly different from that at 2 weeks: $\dagger P<0.05, \dagger \dagger P<0.01$.

tissue (about seven- $v$. four-fold). The greater lipolytic response of the mesenteric tissue in response to the high-fat diet may be part of the explanation as to why exercise training specifically decreases lipolysis in this tissue in this dietary condition. In one of the rare studies that looked at the effects of exercise training on lipolysis in various adipose tissues in normally fed rats, exercise training did increase adrenalinestimulated lipolysis in the retroperitoneal tissue but not in the mesenteric tissue, indicating that these two adipose tissues respond differently to exercise training under normal feeding conditions ${ }^{(23)}$. Altogether, it seems that the effects of exercise training on reducing the elevation in lipolytic activity in highfat-fed rats are particularly observed in the mesenteric tissue, suggesting that this effect might be specific to this visceral adipose tissue.

\section{Basal lipolysis}

Opposite of what was found in the Sed condition (week 8), exercise training did not result in higher levels of basal lipolysis in the mesenteric tissue compared with values at times 0 and 2 weeks (Fig. 1). Interpretation of basal lipolysis in the present study is complicated by the fact that the data were acquired in an in vitro situation, which may not reflect the normal basal in vivo conditions. This situation is not as important when lipolysis is stimulated by pharmacological agents since the stimulation overcomes the normal in vivo environment of the cells. Actually, several in vitro findings related to stimulated lipolysis have been confirmed by in vivo measurements ${ }^{(23)}$. Notwithstanding the limitation of the in vitro measurements, the absence of a high rate of basal lipolysis in the mesenteric tissue of Tr rats fed a high-fat diet would be highly beneficial from a metabolic point of view by potentially decreasing the circulating levels of NEFA reaching the liver in the resting state and potentially reducing liver fat accumulation. It is not clear if exercise training affects basal lipolysis in normally fed human subjects and animals. Exercise training has been reported to be without effect or may reduce basal lipolysis in some fat depots in normally fed animals ${ }^{(19,23)}$. The present data are, however, the first to indicate that exercise training limits the increase in basal in vitro lipolysis in the mesenteric fat depot of high-fat-fed rats.

\section{Exercise and visceral adipose tissue in humans}

It is well documented that visceral fat constitutes an important risk factor for the development of metabolic abnormalities and CVD in humans ${ }^{(13)}$. Exercise training decreases visceral fat and this is associated with an improvement in glucose disposal and insulin sensitivity ${ }^{(25)}$. Recent evidence suggests that the improvement in insulin sensitivity with exercise training may be explained by a decreased availability of $\mathrm{NEFA}^{(26)}$. A reduction in lipolytic activity of the visceral fat depot with exercise training could, therefore, contribute to the reduced availability of NEFA to the portal system and to the improvement in insulin sensitivity in obese individuals.

\section{Lipolysis and perilipin}

It is not readily apparent as to what mechanism might explain the exercise training-induced attenuation in the lipolytic activity of the mesenteric tissue in the present high-fat-fed rats. Plasma glucose and insulin were increased to a similar extent in Sed and Tr animals after 8 weeks of high-fat feeding. Nomura et al. ${ }^{(19)}$ observing that basal activity of HSL was greater in Tr normally fed rats, but basal lipolysis was not, recalled the suggestion of a dual mechanism of lipolytic activation of lipolysis involving some factor on the surface of the lipid droplets (i.e. perilipin) that may be necessary for the hormonal stimulation of lipolysis ${ }^{(27)}$. In an attempt to explore this mechanistic avenue, perilipin content was measured in the mesenteric tissue of the present $\mathrm{Tr}$ and Sed animals. Interestingly, our data indicate a transient increase in perilipin content in absolute values after 2 weeks that decreased to initial values after 8 weeks (Fig. 3 (A)). This resulted in low perilipin content in relation to fat mass accretion after 8 weeks (Fig. 3 (B)). Since perilipin has been reported to be involved in the mechanism of stimulation of lipolysis ${ }^{(23,28)}$, the low level of perilipin expressed per unit of fat mass after 8 weeks may explain the increase in lipolysis in the present high-fat-fed rats kept in 
the Sed state. It is not clear what caused the decrease in perilipin content after 8 weeks of high-fat feeding. It could be related to the increased plasma leptin levels. Mice overexpressing leptin show a reduction in perilipin gene expression in white adipose tissue ${ }^{(29)}$. On the other hand, and most importantly, exercise training did not significantly affect perilipin content in the mesenteric tissue, whether reported in absolute or in relative values. The association between perilipin content and lipolysis is, however, complicated by the fact that other factors in addition to HSL and perilipin may contribute to the lipolytic response ${ }^{(30)}$. The new enzyme adipose TAG lipase, that catalyses the initial step in TAG hydrolysis in mammalian adipose tissue, along with the adipocyte lipid-binding proteins that interact with HSL favouring the translocalisation from cytosol to lipid droplet, are potential candidates $^{(31,32)}$.

In summary, results of the present study indicate that exercise training lowers the elevation in stimulated in vitro lipolytic activity in the mesenteric tissue of rats concurrently fed with a high-fat diet. This effect was not observed in a nonvisceral tissue (retroperitoneal) and seems to be independent of the perilipin content. Whether exercise training may decrease the lipolytic activity of the visceral adipose tissue of established obese individuals and thus constitute a healthpromoting effect remains to be established.

\section{Acknowledgements}

The present study was supported by grants from the Natural Sciences and Engineering Research Council of Canada (J.-M. L.) and from the Canadian Institutes of Health Research (J.-M. L. and P. I.) of Canada.

There is no conflict of interest of any of the authors involved the present study. N. C. and P. Collins have been involved in all steps of the collection of the data, while P. I. and P. Corriveau have been involved in the technical aspects and the collection of the data. J.-M. L. and N. C. have been involved in the planning of the experiment and the writing of the manuscript. All authors have contributed to the correction of the manuscript.

\section{References}

1. Stich V \& Berlan M (2004) Physiological regulation of NEFA availability: lipolysis pathway. Proc Nutr Soc 63, 369-374.

2. Scheen AJ \& Luyckx FH (2002) Obesity and liver disease. Best Pract Res Clin Endocrinol Metab 16, 703-716.

3. Bosello O \& Zamboni M (2000) Visceral obesity and metabolic syndrome. Obes Rev 1, 47-56.

4. Kraegen EW, Storlien LH, Jenkins AB \& James DE (1989) Chronic exercise compensates for insulin resistance induced by a high-fat diet in rats. Am J Physiol 256, E242-E249.

5. Ghibaudi L, Cook J, Farley C, van Heek M \& Hwa JJ (2002) Fat intake affects adiposity, comorbidity factors, and energy metabolism of Sprague-Dawley rats. Obes Res 10, 956-963.

6. Gauthier MS, Couturier K, Latour JG \& Lavoie JM (2003) Concurrent exercise prevents high-fat-diet-induced macrovesicular hepatic steatosis. J Appl Physiol 94, 2127-2134.

7. Gauthier MS, Couturier K, Charbonneau A \& Lavoie JM (2004) Effects of introducing physical training in the course of a 16-week high-fat diet regimen on hepatic steatosis, adipose tissue fat accumulation, and plasma lipid profile. Int $J$ Obes Relat Metab Disord 28, 1064-1071.

8. Berger JJ \& Barnard RJ (1999) Effect of diet on fat cell size and hormone-sensitive lipase activity. J Appl Physiol 87, 227-232.

9. Collin P, Chapados N, Dufresne E, Corriveau P, Imbeault P \& Lavoie JM (2006) Time course of changes in in vitro lipolysis of intra-abdominal fat depots in relation to high-fat diet-induced hepatic steatosis in rats. Br J Nutr 96, 268-275.

10. Bukowiecki L, Lupien J, Follea N, Paradis A, Richard D \& LeBlanc J (1980) Mechanism of enhanced lipolysis in adipose tissue of exercise-trained rats. Am J Physiol 239, E422-E429.

11. Crampes F, Beauville M, Riviere D \& Garrigues M (1986) Effect of physical training in humans on the response of isolated fat cells to epinephrine. J Appl Physiol 61, 25-29.

12. Borges-Silva CN, Fonseca-Alaniz MH, Alonso-Vale MI, Takada J, Andreotti S, Peres SB, Cipolla-Neto J, Pithon-Curi TC \& Lima FB (2005) Reduced lipolysis and increased lipogenesis in adipose tissue from pinealectomized rats adapted to training. J Pineal Res 39, 178-184.

13. Votruba SB \& Jensen MD (2007) Regional fat deposition as a factor in FFA metabolism. Ann Rev Nutr 27, 149-163.

14. Lönnqvist F, Thöme A, Nilsell K, Hoffstedt J \& Arner P (1999) A pathogeneic role of visceral fat $\beta$-3-adrenoreceptors in obesity. J Clin Invest 95, 1109-1116.

15. Greenberg AS, Egan JJ, Wek SA, Garty NB, Blanchette-Mackie EJ \& Londos C (1991) Perilipin, a major hormonally regulated adipocyte-specific phosphoprotein associated with the periphery of lipid storage droplets. J Biol Chem 266, 11341-11346.

16. Londos C, Brasaemle DL, Schultz CJ, Segrest JP \& Kimmel AR (1999) Perilipins, ADRP, and other proteins that associate with intracellular neutral lipid droplets in animal cells. Semin Cell Dev Biol 10, 51-58.

17. Brasaemle DL, Rubin B, Harten IA, Gruia-Gray J, Kimmel AR \& Londos C (2000) Perilipin A increases triacylglycerol storage by decreasing the rate of triacylglycerol hydrolysis. J Biol Chem 275, 38486-38493.

18. Tansey JT, Sztalryd C, Gruia-Gray J, Roush DL, Zee JV, Gavrilova O, Reitman ML, Deng CX, Li C, Kimmel AR \& Londos C (2001) Perilipin ablation results in a lean mouse with aberrant adipocyte lipolysis, enhanced leptin production, and resistance to diet-induced obesity. Proc Natl Acad Sci U S A 98, 6494-6499.

19. Nomura S, Kawanami H, Ueda H, Kizaki T, Ohno H \& Izawa $T$ (2002) Possible mechanisms by which adipocyte lipolysis is enhanced in exercise-trained rats. Biochem Biophys Res Commun 295, 236-242.

20. Rodbell M (1964) Metabolism of isolated fat cells. I. Effects of hormones on glucose metabolism and lipolysis. $J$ Biol Chem 239, 375-380.

21. Coe NR, Simpson MA \& Bernlohr DA (1999) Targeted disruption of the adipocyte lipid-binding protein (aP2 protein) gene impairs fat cell lipolysis and increases cellular fatty acid levels. J Lipid Res 40, 967-972.

22. Iglesias-Osma MC, Garcia-Barrado MJ, Visentin V, PastorMansilla MF, Bour S, Prevot D, Valet P, Moratinos J \& Carpene C (2004) Benzylamine exhibits insulin-like effects on glucose disposal, glucose transport, and fat cell lipolysis in rabbits and diabetic mice. J Pharmacol Exp Ther 309, 1020-1028.

23. Enevoldsen LH, Stallknecht B, Fluckey JD \& Galbo H (2000) Effect of exercise training on in vivo lipolysis in intra-abdominal adipose tissue in rats. Am J Physiol Endocrinol Metab 279, E585-E592.

24. Cinti S (2005) The adipose organ. Prostaglandins Leukot Essent Fatty Acids 73, 9-15.

25. Ross R, Dagnone D, Jones PJ, Smith H, Paddags A, Hudson R \& Janssen I (2000) Reduction in obesity and related comorbid conditions after diet-induced weight loss or exercise-induced 
weight loss in men. A randomized, controlled trial. Ann Intern Med 133, 92-103.

26. Shojaee-Moradie F, Baynes KC, Pentecost C, et al. (2007) Exercise training reduces fatty acid availability and improves the insulin sensitivity of glucose metabolism. Diabetologia 50, 404-413.

27. Wise LS \& Jungas RL (1978) Evidence for a dual mechanism of lipolysis activation by epinephrine in rat adipose tissue. $J$ Biol Chem 253, 2624-2627.

28. Enevoldsen LH, Stallknecht B, Langfort J, Petersen LN, Holm C, Ploug T \& Galbo H (2001) The effect of exercise training on hormone-sensitive lipase in rat intra-abdominal adipose tissue and muscle. J Physiol 536, 871-877.
29. Ke Y, Qiu J, Ogus S, Shen W-J, Kraemer FB \& Chehab FF (2003) Overexpression of leptin in transgenic mice leads to decreased basal lipolysis, PKA activity, and perilipin levels. Biochem Biophys Res Comm 312, 1165-1170.

30. Sztalryd C, Xu G, Dorward H, Tansey JT, Contreras JA, Kimmel AR \& Londos C (2003) Perilipin A is essential for the translocation of hormone-sensitive lipase during lipolytic activation. J Cell Biol 161, 1093-1103.

31. Zimmermann R, Strauss JG, Haemmerle G, et al. (2004) Fat mobilization in adipose tissue is promoted by adipose triglyceride lipase. Science 306, 1383-1386.

32. Carmen GY \& Victor SM (2006) Signalling mechanisms regulating lipolysis. Cell Signal 18, 401-408. 